HORMONE

RESEARCH IN

PAEDIATRICS

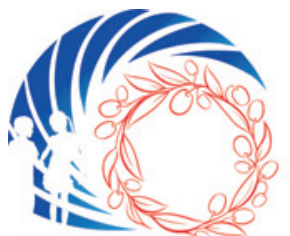

57th ESPE 2018

Meeting ATHENS GREECE

27-29 September 2018

\section{7th Annual Meeting of the European Society for Paediatric Endocrinology (ESPE)}

Athens, Greece, September 27-29, 2018

Guest Editor

George P. Chrousos, Athens, Greece

Programme Organising Committee

Mehul Dattani, UK, Chair

George P. Chrousos, Greece, President 2018

Bessie Spiliotis, Greece, Vice-President 2018

Gabriele Haeusler, Austria, President-Elect 2019

Evangelia Charmandari, Greece

Nils Krone, UK

Zdenek Sumnik, Czech Republic

Dov Tiosano, Israel

Local Organising Committee

George P. Chrousos, President

Bessie Spiliotis, Vice-President

Evangelia Charmandari, Secretary

Christine Kanaka-Gantenbein, Treasurer

Assimina Galli-Tsinopoulou

Maria Karantza

Maria Alexandra Magiakou

Athanasios Christoforidis

Dionysios Chrysis

Catherine Dacou-Voutetakis

Fotini-Eleni Karachaliou

Eirini Kostopoulou

Sarantis Livadas

Anastasios Papadimitriou

Dimitrios Papadimitriou

Maria Papagianni

Nicos Skordis

Lela Stamogiannou

Antony Voutetakis

Elpis Vlachopapadopoulou

Maria Alevizaki

Theodore Alexandridis

George Mastorakos

Tzant Mouslech

Stylianos Tsagarakis

Agathoklis Tsatsoulis 


\section{This publication was sponsored by}

\author{
Merck KGaA \\ Novo Nordisk \\ Pfizer Inc. \\ Sandoz
}

S. Karger

Medical and Scientific Publishers

Basel $\cdot$ Freiburg $\cdot$ Paris $\cdot$ London ·

New York $\cdot$ Chennai $\cdot$ New Delhi

Bangkok $\cdot$ Beijing $\cdot$ Shanghai $\cdot$ Tokyo Kuala Lumpur $\cdot$ Singapore $\cdot$ Sydney
Disclaimer

The statements, opinions and data contained in this publication are solely those of the individual authors and contributors and not of the publisher and the editor(s). The appearance of advertisements in the journal is not a warranty, endorsement, or approval of the products or services advertised or of their effectiveness, quality or safety. The publisher and the editor(s) disclaim responsibility for any injury to persons or property resulting from any ideas, methods, instructions or products referred to in the content or advertisements.

Drug Dosage

The authors and the publisher have exerted every effort to en sure that drug selection and dosage set forth in this text are in accord with current recommendations and practice at the time of publication. However, in view of ongoing research, changes in government regulations, and the constant flow of information relating to drug therapy and drug reactions, the reader is urged to check the package insert for each drug for any change in indications and dosage and for added warnings and precautions. This is particularly important when the recommended agent is a new and/or infrequently employed drug.
All rights reserved.

No part of this publication may be translated into other languages, reproduced or utilized in any form or by any means, electronic or mechanical, including photocopying, recording microcopying, or by any information storage and retrieval system, without permission in writing from the publisher or, in the case of photocopying, direct payment of a specified fee to the Copyright Clearance Center (see 'General Information').

(c) Copyright 2018 by S. Karger AG,

P.O. Box, $\mathrm{CH}-4009$ Basel (Switzerland) e-ISBN 978-3-318-06418-6

\section{KARGER}




\title{
Contents
}

\author{
Plenary Lectures \\ PL1 Oncofertility: From Bench to Bedside to Babies \\ PL2 Oxytocin and the Healing Power of Love \\ PL3 Clinical and Molecular Genetics of Corticothroph Pituitary Tumours \\ (Cushings Disease) \\ PL4 Prediction, Identification, and Treatment of Early Stage Type 1 Diabetes \\ PL5 Dynamic Control of Tissue Glucocorticoids - Lessons for Optimising Replacement 5 \\ Therapy \\ PL6 Personalized Treatments Using Gut Microbiome and Clinical Data \\ PL7 New Curative Treatment Strategies for Type 1 Diabetes \\ PL8 Turner Syndrome: New Insights from Prenatal Genomics and Transcriptomics
}

\section{Symposia}

S1 Recent Developments in the Understanding of Hypothalamo-Pituitary Disorders

S3 Recent Consensus Guidelines

S4 Management of Lafe Effects of Cancer Therapy

S5 ISPAD - ESPE Preventing Late Complications in Children with T1D

S6 Molecular Mechanisms of Tissue Sensitivity to Glucocorticoids: Potential Clinical

\section{S9 Novel Advances in Endocrine Imaging}

S10 Paediatric Obesity: Mechanisms and Novel Treatment

SS1 Special Symposia: Nutrition and Growth

\section{Meet the Expert}

MTE1.1 The Role of Radiology in the Diagnosis of Skeletal Dysplasias $\quad 1.1$

MTE2.1 Endocrine Complications in Thalassaemia 2.1

MTE4.1 The Use of Modern Technologies to Optimize Diabetes Care $\quad 4.1$

MTE5.1 Gonadal Function in Congenital Adrenal Hyperplasia (CAH) $\quad 5.1$

MTE6.1 Management of Hypo and Hypercalcaemia $\quad 6.1$

MTE8.1 Psychology of Childhood Diabetes: How to Motivate Children and Families with $\quad 8.1$

17 Novel Advances \& Controversies in Paediatric Endocrinology

17 NA The Clinical Relevance of Metabolomics; Genomic Engineering - CRISP-R/Cas9 and Its Many Implications

\section{Henning Anderson Award}

HA1 EAP1 Mutations Cause an Impaired Transcriptional Activity on GnRH Promoter that Leads to Self-Limited Delayed Puberty 


\section{Working Groups}

WG1 ESPE Disorders of Sex Development \& Turner Syndrome Joint Session

\section{Free Communications}

FC1 Adrenals \& HPA Axis

$1.1-1.6$

FC2 Bone, Growth Plate \& Mineral Metabolism 1

$2.1-2.6$

FC3 Diabetes and Insulin 1

FC4 GH \& IGFs

FC5 Thyroid

FC6 Fat, Metabolism and Obesity

FC7 Fetal, Neonatal Endocrinology and Metabolism

FC8 Sex differentiation, Gonads and Gynaecology or Sex Endocrinology

FC9 Pituitary, Neuroendocrinology and Puberty 1

FC10 Late Breaking

FC11 Bone, Growth Plate \& Mineral Metabolism 2

FC12 Diabetes and Insulin 2

FC13 Pituitary, Neuroendocrinology and Puberty 2

FC14 Multisystem Endocrine Disorders

$3.1-3.6$

$4.1-4.6$

$5.1-5.6$

$6.1-6.6$

$7.1-7.6$

$8.1-8.6$

$9.1-9.6$

$10.1-10.6$

$11.1-11.6$

$12.1-12.6$

$13.1-13.6$

FC15 Growth and Syndromes

$14.1-14.6$

$15.1-15.6$

\section{Rapid Free Communications}

\section{RFC1 Adrenals \& HPA Axis}

$1.1-1.6$

RFC2

Bone, Growth Plate \& Mineral Metabolism 1

RFC3

Diabetes and Insulin 1

RFC4

GH \& IGFs

RFC5

Thyroid

RFC6

Fat, Metabolism and Obesity

RFC7

Fetal, Neonatal Endocrinology and Metabolism

RFC8

Sex Differentiation, Gonads and Gynaecology or

RFC9

Pituitary, Neuroendocrinology and Puberty 1

RFC10 Late Breaking

RFC11

Bone, Growth Plate \& Mineral Metabolism 2

$2.1-2.6$

$3.1-3.6$

$4.1-4.6$

$5.1-5.6$

$6.1-6.6$

$7.1-7.6$

$8.1-8.6$

$9.1-9.6$

$10.1-10.6$

RFC12 Diabetes and Insulin 2

RFC13 Pituitary, Neuroendocrinology and Puberty 2

RFC14 Multisystem Endocrine Disorders

$11.1-11.6$

$12.1-12.6$

$13.1-13.6$

RFC15

Growth and Syndromes

$14.1-14.6$

$15.1-15.6$

\section{5}

\section{Poster Presentations}

Adrenals and HPA Axis P1

Adrenals and HPA Axis P2

$\mathrm{P} 1-\mathrm{P} 001$ - P1-P024

Adrenals and HPA Axis P3

$\mathrm{P} 2-\mathrm{P} 001$ - $\mathrm{P} 2-\mathrm{P} 035$

P3-P001 - P3-P030;

P3-P404; P3-P414

Bone, Growth Plate \& Mineral Metabolism P1

Bone, Growth Plate \& Mineral Metabolism P2

$\mathrm{P} 1-\mathrm{P} 025$ - P1-P039

P2-P036 - P2-P059

Bone, Growth Plate \& Mineral Metabolism P3

P3-P031 - P3-P062;

P3-P064 - P3-P070

Diabetes \& Insulin P1

$\mathrm{P} 1-\mathrm{P} 040$ - P1-P092

Diabetes \& Insulin P2 
P3-P071 - P3-P124

P3-P399; P3-P403;

P3-P407; P3-P416;

Late Breaking P1

GH \& IGFs P1

GH \& IGFs P3

Thyroid P1

Thyroid P2

Thyroid P3
Fat, Metabolism and Obesity P1

Fat, Metabolism and Obesity P2

Fat, Metabolism and Obesity P3

Fetal, Neonatal Endocrinology and Metabolism P1

Fetal, Neonatal Endocrinology and Metabolism P2

Fetal, Neonatal Endocrinology and Metabolism P3

GH \& IGFs P2

Growth \& Syndromes P1

Growth \& Syndromes P2

Growth \& Syndromes P3

Multisystem Endocrine Disorders P1

Multisystem Endocrine Disorders P2

Multisystem Endocrine Disorders P3

Pituitary, Neuroendocrinology and Puberty P1

Pituitary, Neuroendocrinology and Puberty P2

Pituitary, Neuroendocrinology and Puberty P3

Sex Differentiation, Gonads and Gynaecology or Sex Endocrinology P1 Sex Differentiation, Gonads and Gynaecology or Sex Endocrinology P2 Sex Differentiation, Gonads and Gynaecology or Sex Endocrinology P3

648

\section{Author Index}

